\begin{abstract}
J ournal of Nobel Medical College
A vailable Online: www.nepjol.info, www.nobelmedicalcollege.com.np

Volume 5, Number 2, Issue 9, Aug.-Dec. 2016, 37-42
\end{abstract}

\title{
Original Article \\ An open label study on Depression Patient's Disability Outcomes:
Comparative Evaluation of Escitalopram and Amisulpride
}

Vijay Kaul*, Shaktibala Dutta, Mirza Atif Beg, Nand Kishore Singh, Shalu Bawa, Mohammad Anjoom, Srihari Dutta, Prithi Rai

Department of Psychiatry, Nobel Medical College \& Teaching Hospital, Kanchanbari, Biratnagar Received:2 $1^{\text {th }}$ September 2016; Revised after peer-review: $15^{\text {th }}$ October, 2016; Accepted:22 ${ }^{\text {th }}$ November, 2016

\begin{abstract}
Background

Depression is an important global public health problem due to its relatively high lifetime prevalence and significant disability caused by it. The present study was conducted to compare improvement in disability outcome by Amisulpride and Escitalopram among depression patients using WHO-Disability Assessment Schedule (WHO-DAS).

Materials and Methods

The study was conducted in depression patients for 1 year in the Department of Neuropsychiatry, Nepalgunj Medical College \& Teaching Hospital. A total of 117 depression patients were divided into 2 groups. Group I (58 patients) received Amisulpride tablet at a dose of $50 \mathrm{mg} /$ day and Group II (59 patients) were given Escitalopram at a dose of $10 \mathrm{mg} /$ day. The patients were required to follow up at 4 weeks, 8 weeks and at 15 weeks. The efficacy of the drugs was calculated by Hamilton depression rating scale (HAM-D). The improvement in functional outcome was compared between the two groups by using WHO-Disability Assessment Schedule (WHO-DAS). Appropriate statistical tools using GraphPadInstat 3.0 were used for analysis. $p$ value $<0.05$ was considered significant.
\end{abstract}

Results

HAM-D score in group receiving Amisulpride at 0 and 15 weeks was $16.92 \pm 0.35$ and $7.87 \pm 0.29(p<0.0001)$. HAM-D score in group receiving Escitalopram at 0 and 15 weeks was $17.09 \pm 0.39$ and $6.63 \pm 0.39(p<0.0001)$. WHO-DAS score in group receiving Amisulpride at 0 and 15 weeks was $112.54 \pm 0.82$ and $43.08 \pm 1.41 \quad(p<0.0001)$ respectively. WHO-DAS in group receiving Escitalopram at 0 and 15 weeks was $113.73 \pm 1.92$ and $40.69 \pm 1.49(p<0.0001)$ respectively. Intergroup comparison at 15 weeks was insignificant $(p>0.05)$. Gastrointestinal disturbances, sexual disturbances, amenorrhea, lactation, agitation and insomnia were the commonly encountered adverse drug reactions.

Conclusion

Both Amisulpride and Escitalopram showed improvement in WHO Disability Assessment Score (WHO-DAS) at the end of study period. But intergroup comparison showed no significant difference in the two groups.

Key words: Depression, Amisulpride, Escitalopram, WHO Disability Assessment Schedule (WHO-DAS). 
Vijay Kaul, et.al., J ournal of Nobel Medical College

Introduction

Depression is a commonly occurring, serious, recurrent disorder linked to diminished role functioning and quality of life, medical morbidity, and mortality [1]. The World Health Organization (WHO) has ranked depression the 4 th leading cause of disability worldwide and projects that by 2020 , it will be the second leading cause. The WHO defines depression as a pessimistic sense of inadequacy and a despondent lack of activity. The accompanying signs include psychomotor retardation or at times, withdrawal from interpersonal contact and vegetative symptoms such as anorexia and insomnia. Depression is associated with marked personal, social and economic morbidity affecting $9.5 \%$ of population worldwide [2].

First-line pharmacotherapy for depressive disorders is typically chosen from among the "newer antidepressants" - either a selective serotonin reuptake inhibitor (SSRI) or a serotonin-norepinephrine reuptake inhibitor (SNRI) [3]. Escitalopram, the Senantiomer of citalopram, is a selective serotonin reuptake inhibitor (SSRI) antidepressant that is the most selective of the SSRIs [4]. However, a number of well controlled clinical trials, metaanalyses and practical clinical studies have found that only a third of such depression patients remit following adequate antidepressant treatment, while most depression patients suffer from significant core depressive or residual symptoms during their clinical course. There have been some treatment approaches to overcome such a shortage of antidepressant efficacy, such as augmentation of psychotropics other than antidepressants, switching to a different antidepressant and combinations of different antidepressants [5].

Recently, second generation antipsychotics (SGAs), have clearly demonstrated efficacy in the treatment of depression patients through a number of small scale, open label studies or randomized, placebo controlled clinical trials. Amisulpride is a substituted benzamide derivative structurally related to sulpiride. It belongs to the secondgeneration antipsychotic that preferably binds to dopamine D2/D3 receptors in limbic rather than striatal structures [6]. Amisulpride is indicated for the treatment of acute and chronic schizophrenia with prominent positive and/or negative symptoms due to a dose-dependent blockade of dopamine receptors [6]. In addition to antipsychotic effects, preliminary reports suggest that Amisulpride may have antidepressant effects in dysthymia. Amisulpride has been show $\mathrm{n}$ to be as effective as comparator in clinical studies in patients with dysthymia and/or major depression [7]. The presumed selectivity of amisulpride for D2 and D3 dopamine receptors has led to the prevailing hypothesis that modulation of dopaminergic signaling is responsible for its antidepressant efficacy.

Along with traditional indicators of a population's health status, such as mortality and morbidity rates, disability has become important in measuring disease burden, in evaluating the effectiveness of health interventions and in planning health policy [8]. Defining and measuring disability, however, has been challenging. The WHO-DAS is a semi-structured interview with an informant and with the patient to elicit responses to a number of questions on several areas of functioning: self-care, social withdraw al, participation in the household, relationship with spouse or partner, occupational role and general interests. WHO-DAS has the potential to serve as a reliable and valid tool for assessing functioning and disability across countries, populations and diseases [8]. In this regard, emerging data show that escitalopram has an ability to improve functional outcomes in depression patients 
Vijay Kaul, et.al., J ournal of Nobel Medical College

[9]. Based on the above observations, the present study was conducted to compare efficacy of Amisulpride and Escitalopram by HAM-D and improvement in functional outcomes by WHODAS among depression patients in a tertiary care teaching hospital in Nepal.

Materials and Methods

This study was conducted in the Department of Neuropsychiatry, Nepalgunj Medical College \& Teaching Hospital, Nepalgunj, for a period of 1 year from the month of J anuary 2013 till December 2013. Institutional Ethics Committee approval and written informed consent from the patients or legal guardians were taken prior to the commencement of the study. Inclusion Criteria: a. All drug naive patients attending the Neuropsychiatry OPD, of both sexes who were diagnosed as $F$ 34.1, according to ICD 10 (World Health Organization, 2008). b. Score $\geq 14$ points on the Hamilton Depression Rating Scale (1980) on the first screening visit. Exclusion Criteria: a. Use of psychoactive substances b. any systemic illness $c$. lactating and pregnant women $d$. known case of psychiatric illness as described by ICD 10 (World Health Organization, 2008), e. History of Drug reaction.

Study Design: The study was an open label study conducted from J anuary 2013 to December 2013. A total of 117 patients diagnosed with depression were randomly divided in two groups: Group I (58 patients) received tablet Amisulpride 50 mg/day orally and Group II (59 patients) were given tablet Escitalopram $10 \mathrm{mg} /$ day orally. The efficacy of the drugs was calculated by Hamilton depression rating scale (HAM-D). The improvement in functional outcome was compared between the two groups by using WHODisability Assessment Schedule (WHODAS). Drug compliance was monitored rigorously by providing drug calendars where time of medicines were specified daily but no drug blood levels were monitored due to lack of any such facility locally. The patients were followed up at 4, 8 and 15 weeks. The patients were contacted telephonically and reminded about their follow ups. Adverse drug reactions were monitored at every follow up. Appropriate statistical tools using Graph Padlnstat 3.0 were used for analysis. $p$ value $<0.05$ was considered significant.

Results

Out of a total of 117 patients which were included in the study, 18 patients dropped out from the study due to varying reasons: 6 patients were lost to follow up, 6 patients were lost due to

Figure 1: Flow chart of patients who completed the study

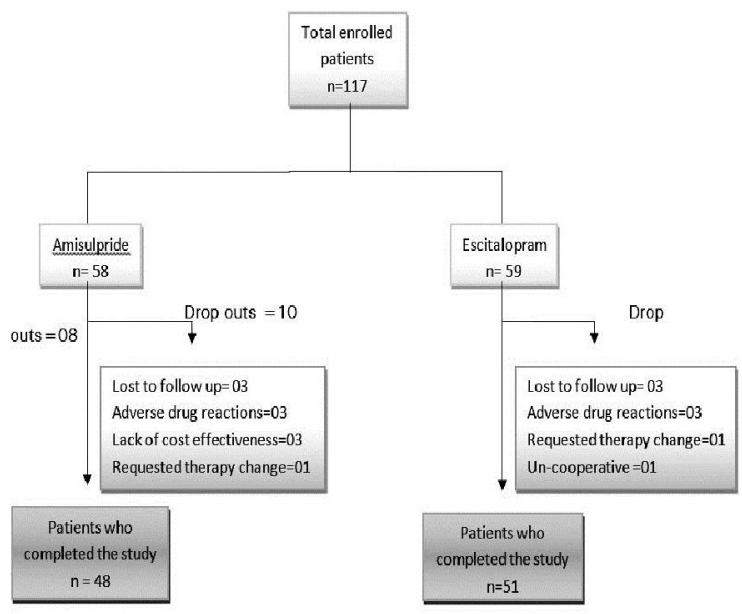

adverse drug reactions, 3 patients were lost due to lack of cost effectiveness, 2 patients requested therapy change and 1 patient was uncooperative. Overall, 99 patients completed the study: 48 patients in Amisulpride group and 51 patients in Escitalopram group (figure 1 ).

The mean age of the patients in the study drug groups was 46.84 10.94 years. The male: female \%age was $41(41.41 \%)$ and 58(58.59\%). In our study, $31(31.31 \%)$ patients were residing in urban areas and 68(68.69\%) patients were residing in rural areas. A total of 
Vijay Kaul, et.al., J ournal of Nobel Medical College

$47(47.47 \%)$ patients were illiterate and $52(52.53 \%)$ patients were literate. $65(65.66 \%)$ patients were farmers, $23(23.23 \%)$ patients were employed and $11(11.11 \%)$ belonged to others category (table1).

Table 1: Demographic Profile of study group

(All the values are expressed in Mean \pm SD)

\begin{tabular}{|c|c|c|}
\hline Variables & \multicolumn{2}{|l|}{ Total } \\
\hline Age (M ean) & \multicolumn{2}{|c|}{$46.84 \pm 10.94$} \\
\hline $\operatorname{Sex}(M: F)$ & \multicolumn{2}{|c|}{$41(41.41 \%): 58(58.59 \%)$} \\
\hline Residence: & \multirow{2}{*}{\multicolumn{2}{|c|}{$31: 68(31.31 \%, 68.69 \%)$}} \\
\hline $\begin{array}{l}\text { Z (Urban: } \\
\text { Rural) }\end{array}$ & & \\
\hline Education: & \multirow{2}{*}{\multicolumn{2}{|c|}{$47(47.47 \%)$}} \\
\hline Illiterate & & \\
\hline Literate & \multicolumn{2}{|l|}{$52(52.53 \%)$} \\
\hline Occupation: & \\
\hline Farming & \multicolumn{2}{|l|}{$65(65.66 \%)$} \\
\hline Employed & \multicolumn{2}{|l|}{$23(23.23 \%)$} \\
\hline Others & \multicolumn{2}{|l|}{$11(11.11 \%)$} \\
\hline $\begin{array}{l}\text { Baseline } \\
\text { values }\end{array}$ & $\begin{array}{l}\text { Amisulpride } \\
z\end{array}$ & \\
\hline HAM-D & $6.92 \pm 2.42$ & $\begin{array}{l}17.09 \pm \\
2.78\end{array}$ \\
\hline WHO-DAS & 5.68 & $\begin{array}{l}113.73 \pm \\
13.71\end{array}$ \\
\hline
\end{tabular}

The efficacy of the drugs was calculated by Hamilton depression rating scale (HAMD) and improvement in functional outcomes was measured by WHO-DAS. All values were expressed in Mean $\pm S D$. At 0 week, the HAM-D Score in Amisulpride group was $16.92 \pm 2.42$ and in the Escitalopram group was $17.09 \pm 2.78$ respectively. There was no significant difference between the two groups at the start of study $(p>0.05)$. Patients were followed up at 4,8 and 15 weeks. Progressive improvement was seen in both the groups over the study period. At 15 weeks, the HAM-D score in Amisulpride group was $7.87 \pm 2.01$ and in the
Escitalopram group was $6.63 \pm 2.78$ respectively. Intragroup comparison was done between baseline and 15 weeks and highly significant improvement $w$ as seen in both groups $(p<0.0001)$. At 15 weeks, intergroup comparison was made between the two groups which was insignificant $(p>0.05)$ (table 2).

Table 2: Efficacy as per HAM-D

(All the values are expressed in Mean \pm SD)

\begin{tabular}{|l|l|l|l|}
\hline Drug & $\begin{array}{l}0 \\
\text { w eeks }\end{array}$ & $\begin{array}{l}15 \\
\text { w eeks }\end{array}$ & - value \\
\hline Amisulpride & $\begin{array}{l}16.92 \\
2.42\end{array}$ & $\begin{array}{l}7.87 \\
\pm\end{array}$ & $<0.000$ \\
& & 2.01 & \\
\hline $\begin{array}{l}\text { Escitalopra } \\
\text { m }\end{array}$ & $\begin{array}{l}17.09 \\
\pm 2.78\end{array}$ & $\begin{array}{l}6.63 \\
\pm\end{array}$ & $<0.000$ \\
& & 2.78 & \\
\hline
\end{tabular}

At 0 week, the WHO-DAS in Amisulpride group was $112.54 \pm 5.68$ and in Escitalopram group was 113.73 13.71 respectively. Intergroup comparison was insignificant $(p>0.05)$. At 15 weeks, W HODAS score in Amisulpride group was 43.08 \pm 9.77 and in Escitalopram group was $40.69 \pm 10.64$ respectively (figure 2 ). Intragroup comparison was done between baseline and 15 weeks which was highly significant in both the groups $(p<0.0001)$ (figure 2). Intergroup comparison at the end of study was insignificant $(p>0.05)$ (figure 2).

Figure 2: Comparison of WHO-DAS between the two groups

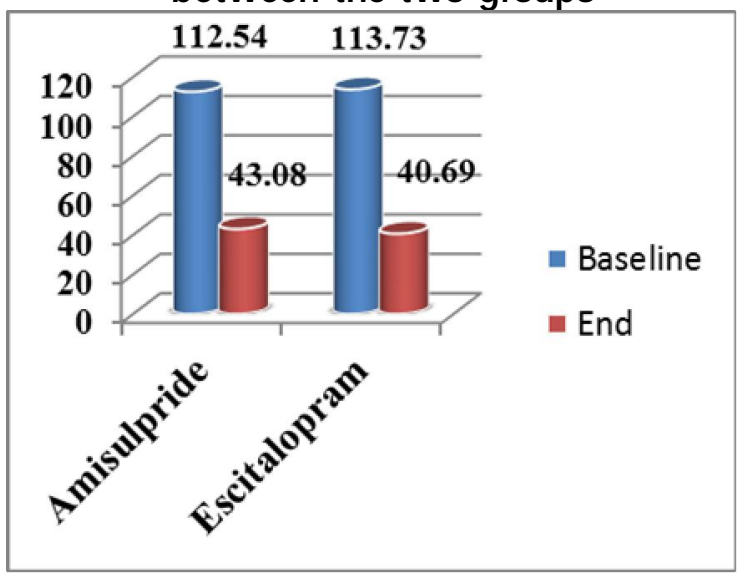


Vijay Kaul, et.al., J ournal of Nobel Medical College

\section{Discussion}

In the present study, there was a higher prevalence of depression in females which was in accordance with previous studies by Ramachandran et al depicting that women were more commonly suffering from depression [10]. The greater prevalence of depression among women is not fully understood, although potential contributors include different responses to stressful life events, genetic predisposition and hormonal differences [11]. The mean age in our study was $46.84 \pm 1$.1years which was comparable with previous studies by Dutta et al where incidence of depression was seen in 30-51 years age group [12]. More depression patients were seen in rural areas as compared to urban areas in the present study. This was comparable with previous studies by Paritala et al, where rural back ground subjects were found to be somatising more than the urban subjects [13]. In our study more number of literates were suffering from depression which was comparable with previous study by Paritala et al [13].

A comparative evaluation of Escitalopram and Amisulpride was done in depression patients by measuring improvement in functional outcome using WHO Disability Assessment Schedule in this 15-week study. Escitalopram is an allosteric selective serotonin reuptake inhibitor (SSRI) with some indication of superior efficacy in the treatment of major depressive disorders. The results of our study revealed highly significant improvement in HAM-D in depressive patients over the study period. Intragroup comparison was made between baseline and 15 weeks in Escitalopram group and highly significant improvement was seen $(p<0.0001)$. This was comparable with previous studies where efficacy of Escitalopram has been proven [14]. Amisulpride, a selective D2/D3 receptor second generation antipsychotic is indicated for the treatment of acute and chronic schizophrenia [15]. The presumed selectivity of amisulpride for D2 and D3 dopamine receptors has led to the prevailing hypothesis that modulation of dopaminergic signaling is responsible for its antidepressant efficacy. In the present study, the antidepressant effect of A misulpride was compared at baseline and at 15 weeks in depressive patients and highly significant improvement was seen $(p<0.0001)$. This was comparable with previous studies by Ravizza L et al where antidepressant role of amisulpride has been proven [16].

Amisulpride has some selectivity for presynaptic dopamine autoreceptors, and exhibits limbic versus striatal selectivity, particularly at low doses, and it has been suggested that this might account for its therapeutic profile [18].

The improvement in functional impairment was measured by WHO-DAS. In the present study, highly significant improvement was seen in both Escitalopram and Amisulpride groups. Previous studies by Kessler RC et al have shown improvement in WHO disability assessment scale with escitalopram [18]. A study by Gutierrenz $F$ et al has shown improvement in WHO-DAS by second generation antipsychotics proving that patients who take medications that are efficacious and acceptable have a better chance of achieving superior functional improvements compared to those who take agents that are less efficacious and/or not as well accepted [19].

At the end of the study period, intergroup comparison was made between Escitalopram group and A misulpride group which revealed no significant difference $(p<0.05)$, indicating both the drug were equally efficacious in improving disability score in depression patients.

Study Limitations: The study was an open label study. Both doctors and patients were aware of the treatments. Hence there 
Vijay Kaul, et.al., J ournal of Nobel Medical College

could be chances of bias. Also, the patients were followed up to only 15 weeks. A longer duration of follow up could have yielded different results.

Conclusion

Both Escitalopram and Amisulpride were highly effective in improving disability outcome in depression patients according to WHO-DAS. But intergroup comparison revealed no significant difference between the two groups.

\section{References}

[1] Spijker J, Graaf R, Bijl RV, Beekman AT, Ormel J, Nolen WA. Functional disability and depression in the general population. Results from the Netherlands Mental Health Survey and Incidence Study (NEMESIS). Acta Psychiatr. Scand. 110 (2004) 208-14.

[2] Kennedy SH, Rizvi SJ . Comparative Efficacy of Newer Antidepressants for Major Depression: A Canadian Perspective. The Canadian J oumal of Diagnosis (2009) 81-6.

[3] Anderson IM, Ferrier IN, Baldwin RC, et al. Evidence-based guidelines for treating depressive disorders with antidepressants: A revision of the 2000 British Association for Psychopharmacology guidelines. Psychopharmacol. 22 (2008) 343-96.

[4] Owens MJ, Knight DL, Nemeroff CB. Secondgeneration SSRIs: human monoamine transporter binding profile of escitalopram and R-fluoxetine. Biol Psychiatry 50 (2001) 34550 .

[5] Montgomery SA, Huusom AKT, Bothmer J . A randomised study comparing escitalopram with venlafaxine $X R$ in primary care patients with major depressive disorder. Neuropsychobiology .50 (2004) 57-64.

[6] Burke WJ , Gergel I, Bose A. Fixed-dose trial of the single isomer SSRI Escitalopram in depressed outpatients. J Clin Psychiatry. 63 (2002) 331-6.

[7] Waugh J, Goa KL. Escitalopram: A review of its use in the management of major depressive and anxiety disorders. CNS Drugs. 17 (2003) 343-62.

[8] American Psychiatric Association. Practice guideline for the treatment of patients with major depressive disorder (revision). Am. J. Psychiatry. 157 (2000) (Suppl. 4) 1-45.

[9] McKeage K, Plosker GL. A misulpride. A review of its use in the management of Schizophrenia. CNS Drugs 18(13) (2004) 93356.
[10] Racagni G, Canonico PL, Ravizza L, Pani L, Amore $M$. Consensus on the use of substituted benzamide in psychiatric patients. Neuropsychobiology .50 (2004) 134-43.

[11] World Health Organization. International classification of functioning, disability and health. Geneva: WHO. (2001).

[12] Kendrick T, Dow rick C, McBride A, et al. Management of depression in UK general practice in relation to scores on depression severity questionnaires: analysis of medical record data. BMJ 338 (2009) b750.

[13] Ramachandran V, Menon MS, Arunagiri S. Socio-cultural factors in late onset depression. Indian J Psychiatry 24 (1982) 268-73.

[14] National Institute of Mental Health. Women and depression, discovering hope, Berthesda, MD: US Department of Health and Human Services, National Institute of Health, National Institute of Mental Health (2009).

[15] Dutta SB, Beg MA, Sindhu S, Singh NK. Role of pharmaco-epidemiology in psychopharmacology: a study in psychiatric out-patient department of a tertiary care teaching hospital at Dehradun, Uttarakhand. Int J Basic Clin Pharmacol 3(4) 2014 637-43.

[16] Paritala CB, Nallapaneni RN, Chennamsetty SK. A cross-sectional study to assess the prevalence of somatisation and associated socio demographic factors in depression. AP J Psychol Med 15(1) (2014) 93-8.

[17] Montgomery SA, Baldw in DS, Blier P, et al. Which antidepressants have demonstrated superior efficacy? A review of the evidence. IntClinPsychopharmacol. 22 (2007) 323- 29.

[18] Perrault G, Depoortere R, Morel E, Sanger DJ , Scatton B. Psychopharmacological profile of amisulpride: an antipsychotic drug with presynaptic D2/D3 dopamine receptor antagonist activity and limbic selectivity. J Pharmacol Exp Ther. 280 (1997) 73-82.

[19] Ravizza L. Amilong investigators. A misulpride in medium-term treatment of dysthymia: a sixmonth, double-blind safety study versus amitriptyline. J Psychopharmacol. 13(3) (1999) 248-54. 